\title{
Dampak Kepemimpinan dan Rotasi Kerja terhadap Turnover Intention
}

\author{
Mochammad Irfan, Arif Rachman Putra* \\ Fakultas Ekonomi, Manajemen, Universitas Mayjen Sungkono, Mojokerto, Indonesia \\ Email: ${ }^{1}$ moc.irfan@gmail.com, ${ }^{2}$ arifrachmanputra.caniago@gmail.com \\ Email Penulis Korespondensi: arifrachmanputra.caniago@gmail.com \\ Submitted: 22/11/2021; Accepted: 29/11/2021; Published: 30/11/2021
}

\begin{abstract}
Abstrak-Salah satu biaya besar yang dikeluarkan oleh perusahaan adalah biaya untuk memelihara sumber daya manusia yang dimiliki. Biaya tersebut terdiri dari biaya rekrutmen dan biaya pelatihan karyawan. Untuk mengurangi biaya tersebut perusahaan perlu menekan angka turnover intention pada perusahaan mereka. Tujuan penelitian ini untuk mengetahui mengetahui dampak kepemimpinan dan rotasi pekerjaan terhadap turnover intention karyawan. Survei ini dengan regresi linear berganda dan SPSS 26 menganalisis data dari 79 responden yang penentuan sampel dilakukan dengan metode sensus. Hasil penelitian ini ditemukan bahwa turnover intention secara parsial dipengaruhi signifikan oleh kepemimpinan. Hasil ini diikuti oleh variabel yang lainnya yaitu rotasi kerja yang secara parsial juga memiliki peran pada turnover intention. Kedua variabel yang diteliti secara simultan berperan pada turnover intention secara nyata dan signifikan.
\end{abstract}

Kata Kunci: Kepemimpinan; Rotasi Pekerjaan; Turnover Intention

Abstract-One of the major costs incurred by the company is the cost to maintain its human resources. These costs consist of recruitment costs and employee training costs. To reduce these costs, companies need to reduce turnover intention in their companies. The purpose of this study was to determine the impact of leadership and job rotation on employee turnover intention. This survey used multiple linear regression and SPSS 26 analyzed data from 79 respondents whose sample was determined using the census method. The results of this study found that turnover intention is partially significantly influenced by leadership. This result is followed by another variable, namely job rotation which partially also has a role in turnover intention. The two variables studied simultaneously play a significant and significant role on turnover intention.

Keywords: Leadership; Job Rotation; Turnover Intention

\section{PENDAHULUAN}

Indikasi ketangguhan atau kekuatan mental karyawan terlihat dari niat mereka untuk bertahan atau berniat meninggalkan pekerjaan di perusahaan. Dari sudut pandang perusahaan, hal ini terlihat dari fluktuasi tingkat turnover karyawan. Angka yang tinggi pada kondisi tersebut mengakibatkan perusahaan mengeluarkan biaya lebih besar untuk memberdayakan karyawan. Ada biaya transisi akibat pergantian. Biaya untuk kesempatan memperoleh karyawan baru lebih tinggi (Kanwal \& Tariq, 2016). Begitu pun biaya yang muncul akibat terjadinya perpindahan kerja karyawan. Keluar atau masuk seperti itu akan berdampak berkelanjutan (Mosadeghrad, 2008).

Kondisi karyawan yang tidak betah pada suatu perusahaan merupakan indikasi dari turnover yang tinggi pada perusahaan tersebut. Hal ini mengakibatkan biaya yang dikeluarkan perusahaan akan lebih banyak lagi. Biaya tersebut digunakan untuk melakukan rekrutmen, pelatihan, dan biaya lain untuk mendukung kerja karyawan seperti lingkungan pekerjaan. Turnover juga mampu menurunkan kepuasan karyawan karena akan terjadi gangguan komunikasi. Hal ini tentu mengakibatkan produktivitas terganggu (Retnowati, 2021). Keadaan ini menjadikan organisasi untuk mencari cara agar turnover dapat menurun sehingga mampu menghemat biaya yang tidak diperlukan dan tidak dapat dikendalikan oleh perusahaan. Itu harus ada tindakan mengantisipasi kemunculan dari turnover intention dari karyawan (Ernawati, 2020).

Turnover intention mengarah kepada intensi perilaku yang menentukan tindakan secara nyata (Hariani, 2019). Niat untuk melakukan turnover sepenuhnya ada di keputusan karyawan sehingga pengamatan yang didasarkan hal tersebut akan memberikan hasil prediksi lebih antisipatif dibanding perilaku nyata turnover itu sendiri (Mueller, 2003).

Turnover intention merupakan gambaran dari kinerja pada organisasi tersebut (Sudja'i \& Arifin, 2021). Selain itu turnover juga menjadi indicator untuk dapat mengetahui tingkat stabilitas pada suatu organisasi. Turnover merupakan keadaan dimana karyawan dengan jumlah tertentu meninggalkan organisasi pada suatu waktu. Turnover intention merupakan kondisi seorang karyawan yang memiliki niat untuk keluar organisasi namun belum melaksanakannya. Ada dua faktor yang berperan terhadap turnover intention karyawan, yaitu kepemimpinan dan rotasi kerja.

Kepemimpinan merupakan kegiatan dan kemampuan seseorang memengaruhi pihak lain (Oetomo, 2004). Menurut Darmawan (2008), kepemimpinan yang efektif itu ada saat seseorang diberikan kekuasaan oleh pemilik usaha untuk bertanggung jawab mengarahkan tugas-tugas tertentu. Organisasi dinyatakan berdaya saat sukses mengolah dan menggerakan sumber daya manusia dengan maksimal (Putra, 2017). Sedangkan karyawan sebagai subjek setiap proses dan kegiatan di lingkungan kerja tentu saja dengan karakteristik seperti motivasi, sasaran, mental, pendidikan, pengalaman yang beragam (Mardikaningsih, 2016). Setiap pemimpin memiliki tantangan untuk mendayagunakan potensi maupun kompetensi karyawan dengan maksimal dan profesional. Kepemimpinan itu seharusnya mampu membuat karyawan memiliki komitmen terhadap perusahaan dan mereka menjadi sumber daya manusia yang produktif (Mardikaningsih, 2020). Kegagalan dari kepemimpinan dapat menyebabkan turnover 
intention karena karyawan sudah tidak merasa nyaman dan mengalami tekanan sehingga memutuskan untuk meninggalkan pekerjaan dan perusahaan (Disch, 2004).

Selain kepemimpinan, rotasi kerja juga memiliki peran turnover intention. Rotasi pekerjaan masuk dalam kelompok pelatihan "on-the-job". Rotasi ditujukan kepada karyawan yang cukup lama bekerja di bidang yang sama (Davis \& Jorgensen, 2005). Adanya rotasi memiliki harapan karyawan mempunyai pengalaman dan kompetensi di ragam bentuk pekerjaan tingkat kesulitan atau posisi yang berbeda di jenjang yang sejenis. Karyawan yang berada dalam pekerjaan yang sama untuk periode kerja yang lama memungkinkan untuk mengalami kejenuhan sehingga kinerja dan produktivitas mereka akan mengalami dinamika fluktuasi (Adjei, 2014). Menurut pandangan manajemen sumber daya manusia, hal ini seharusnya dihindari jangan sampai terjadi dan dialami oleh karyawan. Kondisi tidak sehat ini harus disikapi oleh perusahaan melalui kebijakan rotasi pekerjaan secara berkala. Ini memungkinkan akan menahan keinginan karyawan untuk meninggalkan perusahaan (Werdati, 2020). Meski tidak selalu berjalan sesuai harapan karena dari sudut pandang karyawan, mereka lebih mengutamakan kenyamanan bekerja. Bagi karyawan yang sudah merasa nyaman dengan pekerjaan, hal ini akan memunculkan permasalahan bagi mereka.

Berdasarkan uraian tersebut, diperlukan pantauan terhadap turnover intention dari karyawan yang ditinjau dari aspek kepemimpinan dan rotasi pekerjaan. Apakah kepemimpinan yang tidak tepat dengan kondisi dan tidak memerhatikan kemampuan karyawan akan memberikan dampak kepada turnover intention. Begitu pun rotasi pekerjaan yang belum terancang dengan baik menyebabkan kondisi karyawan yang turnover. Dengan adanya perihal tersebut, studi ini bermaksud mengetahui dampak kepemimpinan dan rotasi pekerjaan terhadap turnover intention karyawan.

\section{METODE PENELITIAN}

Survei ini akan menggunakan analisis regresi sebagai alat untuk menjawab rumusan masalah berupa apakah benar kepemimpinan dan rotasi pekerjaan menyebabkan turnover intention dari karyawan. Pengumpulan data dilakukan dengan penyebaran kuesioner kepada semua karyawan di salah satu perusahaan konveksi di Sidoarjo. Jumlah seluruh pekerja yang dijadikan responden adalah sebanyak 79 orang. Data dari hasil sensus itu akan ditabulasi dan diuji kualitasnya melalui validitas yang dilanjutkan reliabilitas. Hipotesis diujikan dengan alat uji t serta uji F. Pernyataan hipotesis adalah variabel kepemimpinan dan rotasi pekerjaan berpengaruh parsial dan simultan terhadap turnover intention karyawan. SPSS 26 menjadi program statistik di studi ini.

Kepemimpinan merupakan kemampuan seseorang untuk mengajak orang lain melakukan tindakan sesuai dengan rencana yang ditetapkan untuk tujuan tertentu (Putra dan Sinambela, 2021). Menurut Gandhi \& Kumar (2014), dengan kepemimpinan memungkinkan upaya individu dan kolektif untuk bersama-sama mencapai kesejahteraan karyawan dan organisasi. Terdapat 5 indikator kepemimpinan menurut Darmawan dan Mardikaningsih (2021) yaitu 1) memiliki pemikiran ke depan; 2) berani menghadapi berbagai tantangan; 3) mampu membuat keputusan; 4) memiliki komunikasi yang baik; 5) mampu memberikan motivasi.

Rotasi pekerjaan adalah perpindahan secara sistematis karyawan dari satu pekerjaan ke pekerjaan lain pada interval yang direncanakan (Dessler \& Varkkey, 2009). Ini melibatkan perpindahan karyawan secara berkala dari satu tugas ke tugas lainnya di mana setiap tugas membutuhkan keterampilan yang berbeda dan selanjutnya meningkatkan kinerja pekerjaan mereka (Leat, 2007). Rotasi kerja merupakan perubahan kerja karyawan pada waktu tertentu (Mardikaningsih, 2014). Terdapat 5 indikator rotasi kerja menurut Darmawan et al. (2018) yaitu 1) pengalaman; 2) prestasi kerja; 3) kebutuhan; 4) tanggung jawab; dan 5) pengetahuan.

Untuk variabel terikat yang digunakan adalah turnover intention. Turnover intention merupakan sikap yang dimiliki karyawan untuk tidak lagi bekerja di tempat yang sama dengan sukarela (Zeffane, 1999). Indikator turnover intention menurut Mobley et al. (1978) yaitu 1) keinginan untuk keluar dari perusahaan; 2) sikap melakukan pencarian pekerjaan di luar; dan 3) memiliki intensi untuk keluar.

Studi dari Alexandrov (2004), Dupré \& Day (2007), Ernawati (2020), Jahroni (2021) menunjukkan ada peran pemimpin untuk menyebabkan karyawan memiliki pikiran meninggalkan perusahaan. Ini dasar dari hipotesis bahwa kepemimpinan punya peran atas kemunculan turnover intention. Menurut Chen (2015), rotasi pekerjaan memberikan peran terhadap keputusan karyawan untuk tetap bersama organisasi karena menurut mereka, organisasi tidak mereka sebagai sumber daya manusia yang berharga. Ini dasar dari hipotesis bahwa rotasi pekerjaan berperan nyata mencegah turnover intention.

\section{HASIL DAN PEMBAHASAN}

Deskripsi dari responden atau pekerja dari objek penelitian ada 79 orang yang terdiri dari 63 perempuan, dan 16 pria. Ada 27 responden yang baru bekerja kurang dari satu tahun; 35 responden bekerja antara $1-3$ tahun; dan sisanya sudah bekerja di objek pengamatan melebihi rentang 3 tahun. Deskripsi tersebut menunjukkan tingkat turnover intention yang cukup tinggi karena banyaknya pekerja baru dengan alasan mengisi kekosongan yang ditinggalkan oleh pekerja yang keluar.

Uji validitas dengan memperbandingkan $r$ hitung dan $r$ tabel. Berdasarkan hasil SPSS diperoleh fakta nilai $r$ hitung > $r$ tabel. Butir-butir instrumen adalah valid. 
Reliabilitas didasarkan pada nilai koefisien Alpha Cronbach untuk menunjukkan kestabilan pengukuran. Berdasarkan output SPSS, reliabilitas setiap variabel lebih tinggi dari 0.7. Kepemimpinan sebesar 0,793; rotasi pekerjaan sebesar 0,842; dan turnover intention adalah 0,806. Dengan demikian, instrumen tersebut dikatakan reliabel.

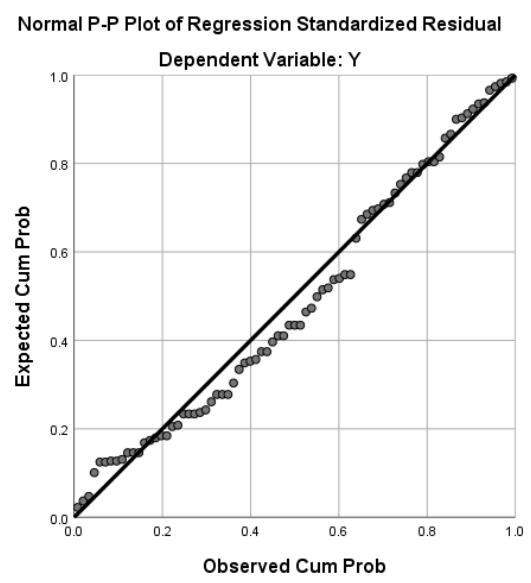

Gambar 1. Normalitas

Data tersebar secara normal seperti yang ditunjukkan pada gambar 1 dan itu memenuhi asumsi normalitas. Hasil analisis regresi berganda ditunjukkan tabel 1. Pada uji t hasil yang diperoleh adalah turnover intention (Y) dipengaruhi oleh kepemimpinan (X.1). Pernyataan ini dibuktikan dengan nilai signifikan yang diperoleh dari hasil analisis di bawah 0,05 . Untuk variabel rotasi kerja (X.2) dapat dikatakan memiliki peran yang signifikan pada turnover intention (Y) sebab nilai signifikan yang diperoleh juga lebih rendah dari $5 \%$.

Tabel 1. Uji t

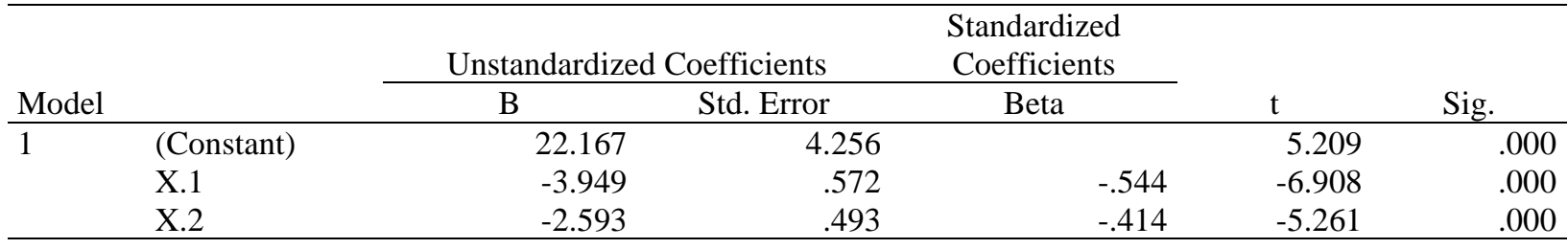

Tabel 1 menghasilkan model regresi $\mathrm{Y}=22.167-3.949 \mathrm{X} .1-2.593 \mathrm{X} .2+$ e. dengan model ini dapat diketahui nilai dari turnover intention sebesar 22.167 jika nilai kepemimpinan dan rotasi pekerjaan bernilai nol. Selanjutnya nilai turnover intention akan berkurang 3,941 jika variabel kepemimpinan naik satu satuan dan variabel rotasi kerja tetap. Hasil ini menunjukkan nilai turnover intention akan berkurang 2,593 jika variabel kepemimpinan bernilai tetap dan rotasi kerja naik satu satuan. Selanjutnya dilakukan uji F.

Hasil analisi pada uji $\mathrm{F}$ di tabel 2 menunjukkan nilai $\mathrm{F}$ yang diperoleh adalah 45,010. Untuk nilai signifikan yang diperoleh adalah 0,000. Dengan demikian penelitian ini menunjukkan bahwa secara simultan turnover intention ditentukan signifikan oleh kepemimpinan dan rotasi kerja.

Tabel 2. Uji F

\begin{tabular}{llrrrrr}
\hline Model & & Sum of Squares & df & Mean Square & F & Sig. \\
\hline 1 & Regression & 1998.579 & 2 & 999.289 & 45.010 & $.000^{\mathrm{b}}$ \\
& Residual & 1687.320 & 76 & 22.202 & & \\
& Total & 3685.899 & 78 & & & \\
\hline
\end{tabular}

Untuk selanjutnya dilakukan uji koefisien determinasi. Hasil penelitian seperti pada tabel 3, dengan besaran $\mathrm{R}$ diperoleh 0,736, sementara koefisien determinasi 0,542. Hasil ini menunjukkan turnover intention ditentukan kepemimpinan dan rotasi kerja sebesar 54,2\%. Variabel lain yang diduga memengaruhi turnover intention yang tidak diteliti pada penelitian ini memngaruhi sebesar 45,8\% sisanya.

Tabel 3. Model Summary ${ }^{\mathrm{b}}$

\begin{tabular}{|c|c|c|c|c|c|}
\hline Model & $\mathrm{R}$ & R Square & Adjusted R Square & $\begin{array}{l}\text { d. Error of the } \\
\text { Estimate }\end{array}$ & Durbin-Watson \\
\hline 1 & $.736^{\mathrm{a}}$ & .542 & .530 & 4.712 & 1.118 \\
\hline
\end{tabular}

Hipotesis yang menyatakan kepemimpinan memiliki peran terhadap intention turnover adalah terbukti benar. Sifat pengaruh adalah negatif yang berarti semakin baik kepemimpinan maka semakin rendah intention turnover 
karyawan. Kepemimpinan yang efektif dapat memahami kemampuan karyawan dengan akurat sehingga proses penempatan berkelanjutan menjadi jalan menuju pengembangan kinerja dan produktivitas kerja. Bila pemimpin tidak berhasil melakukan identifikasi kompetensi karyawan dan gagal menempatkan sesuai dengan bakat dan kemampuannya, maka pemimpin memberikan potensi permasalahan dan kesulitan di masa mendatang. Permasalahan yang bisa terjadi seperti penurunan motivasi kerja serta kemunculan intention turnover dengan tingkat tinggi (Darmawan, 2010).

Hipotesis yang menyatakan bahwa rotasi pekerjaan memiliki dampak terhadap intention turnover juga terbukti benar. Arahnya berlawanan dalam arti semakin baik rotasi pekerjaan maka semakin menurun intention turnover. Rotasi pekerjaan dilakukan untuk mengurangi stress karyawan akibat adanya rutinitas. Dengan adanya rotasi karyawan diharapkan karyawan tidak bosan dengan pekerjaan mereka. Karyawan juga dapat menemukan tantangan baru yang akan menambahkan semangat kerja karyawan. Pelaksanaan rotasi kerja tidak selalu memiliki tanggapan yang positif dari karyawan. Karyawan dapat merasa tidak puas karena sudah merasa nyaman pada pekerjaan ataupun posisi kerja saat ini (Andayani, 2010). Oleh karena itu kebijakan rotasi pekerjaan perlu diinformasikan lebih awal, agar karyawan merasa sudah siap dan menganggap bahwa rorasi pekerjaan merupakan kebijakan yang adil. Manajemen perlu mencari informasi mengenai kinerja dari setiap individu karyawan, pengalaman kerja yang dimiliki, perilaku karyawan tersebut, dan pelatihan yang didapatkan karyawan selama bekerja (Mitchell, 2001). Penting untk manajemen melakukan rotasi pekerjaan sesuai dengan kompetensi yang dimiliki seorang karyawan (Mardikaningsih, 2017). Persiapan karyawan pada pekerjaan baru perlu disiapkan dengan baik agar karyawan siap bekerja pada tempat yang baru.

Selain itu, kepemimpinan dan rotasi pekerjaan terbukti memiliki peran secara simultan dan nyata terhadap intention turnover. Sebagai variabel terikat, intention turnover menunjukkan kecenderungan karyawan untuk berhenti bekerja dari pekerjaannya secara sadar dan atas kehendak sendiri.

\section{KESIMPULAN}

Hasil penelitian ini ditemukan bahwa turnover intention secara parsial dipengaruhi signifikan oleh kepemimpinan. Hasil ini diikuti oleh variabel yang lainnya yaitu rotasi kerja yang secara parsial juga memiliki peran pada turnover intention. Kedua variabel yang diteliti secara simultan berperan pada intention turnover secara nyata dan signifikan. Berdasarkan temuan pada penelitian ini maka diberikan saran sebagai berikut. Bentuk kepemimpinan setiap divisi perlu dievaluasi secara periodik. Hal ini dilakukan untuk mengetahui bentuk kepemimpinan yang efektif bagi karyawan. Perbedaan penerimaan instruksi dari satu karyawan ke karyawan lain, menyebabkan seorang manajer perlu mengetahui bentuk kepemimpinan yang sesuai dan mampu menjadi motivasi dan acuan bagi karyawan. Selain itu rotasi kerja perlu dilakukan dengan sistem yang baik. Rotasi kerja dilakukan sesuai kemampuan dari karyawan tersebut. Untuk itu manajemen perlu mengetahui kinerja dari setiap individu.

\section{REFERENCES}

Adjei, D. (2014). The Impact of Job Rotation on Employees' performance a Case Study: Utrak Financial Services Limited. Strategic Management Journal, 32(4), 343-367.

Alexandrov, A., E. Babakus, \& U. Yavas. (2004). The Effects of Perceived Management concern for frontline employees and customers on turnover intentions, Journal of Service Research, 9(4),356-371.

Andayani, D., S. Kabalmay, R. Resandi, \& D. Darmawan. (2010). Pemberdayaan Karyawan Berbasis Keunggulan Bersaing, IntiPresindo Pustaka, Bandung.

Chen SY, Wen-Chuanwu C, Chang CS, Lin CT. (2015). Job rotation and Internal Marketing for Increased Job Satisfaction and Organizational Commitment in Hospital Nursing Staff. J Nurs Manag. 23(3), 297-306.

Darmawan, D. (2010). Pengaruh Kompetensi Kerja, Budaya Organisasi, Kepemimpinan dan Kompensasi terhadap Loyalitas Kerja, Jurnal Ilmu Sosial, 4(2), 63-76.

Darmawan, D. (2008). Kajian Teoritis Variabel Kepemimpinan, Jurnal Media Komunikasi Ekonomi dan Manajemen, 6(3), 2135 .

Darmawan, D., M. Hariani., E. A. Sinambela. (2018). Dasar Dasar Manajemen Sumber Daya Manusia. Metromedia. Surabaya.

Darmawan, D., E. A. Sinambela, \& M. Hariani, \& M. Irfan. (2020). Analisis Komitmen Organisasi, Iklim Kerja, Kepuasan Kerja dan Etos Kerja yang Memengaruhi Kinerja Pegawai, Jurnal Bisnis dan Kajian Strategi Manajemen, 4(1), 58-70.

Darmawan, D. \& R. Mardikaningsih. (2021). Studi Tentang Peran Kualitas Kehidupan Kerja, Kepemimpinan dan Persepsi Dukungan Organisasi Terhadap Komitmen Organisasi. Jurnal Simki Pedagogia, 4(1), 89-98.

Davis, K, \& M. Jorgensen. (2005). Ergonomics-pros and Cons of Job Rotation as a means of reducing injury costs. J Occup Environ Hyg., 2 (1), 1-3.

Dessler, G., \& B. Varkkey. (2009). Training and Development. Human Resource Management, Dorling Kindersley, New Delhi.

Disch, J., S. Edwardson, \& J. Adwan. (2004). Nursing Faculty Satisfaction with Individual, Institutional, and Leadership Factors. Journal of Professional Nursing, 20, 323-332.

Dupré, K.E. \& A.L. Day. (2007). The Effects of Supportive Management and Job Quality on the turnover intentions and health of military personnel, Human Resource Management, 46(2), 185-201.

Ernawati \& E.A. Sinambela, R. Mardikaningsih, D. Darmawan. (2020). Pengembangan Komitmen Organisasi Melalui Profesionalisme Karyawan dan Kepemimpinan yang Efektif, Jurnal Ekonomi \& Ekonomi Syariah, 3(2), 520-528.

Ernawati \& E. A. Sinambela. (2021). The Effect of Compensation and Career Development on Organizational Commitment, Journal of Engineering \& Social Sciences, 1(1), 24-32. 
Gandhi, D., \& P. Kumar. (2014). Succession Planning: Developing leaders for tomorrow to ensure organizational success. The International Journal of Business \& Management, 2(3), 1.

Hariani, M., S. Arifin, \& A. R. Putra. (2019). Pengaruh Iklim Organisasi, Pengalaman Kerja dan Motivasi Kerja terhadap Komitmen Kerja Karyawan, Management \& Accounting Research Journal, 3(2), 22-28

Issalillah, F. (2020). Kinerja dan Tenaga Kerja, Metromedia, Surabaya.

Jahroni, D. Darmawan, R. Mardikaningsih, \& E. A. Sinambela. (2021). Peran Insentif, Perilaku Kepemimpinan, dan Budaya Organisasi terhadap Penguatan Komitmen Organisasi, Jurnal Ekonomi \& Ekonomi Syariah, 4(2), 1389-1397.

Kanwal, B., \& A. Tariq. (2016). Organizational Environment, Job Satisfaction and Career Growth Opportunities: A link to Employee turnover intentions in university of Sargodha, Pakistan. Journal of Resources Development and Management, $20,8-14$

Leat, M. (2007). Employee Relations and Employment Relationships. Burlington, MA: Elsevier Ltd.

Lestari, U. P. \& E. A. Sinambela, R. Mardikaningsih, \& D. Darmawan. (2020). Pengaruh Efikasi Diri dan Lingkungan Kerja terhadap Kepuasan Kerja Karyawan, Jurnal Ekonomi \& Ekonomi Syariah, 3(2), 529-536.

Mardikaningsih, R. (2014). Kinerja Karyawan dan Faktor-Faktor yang memengaruhinya. Jurnal Ilmu Sosial, 7(2), 73-84.

Mardikaningsih, R. (2016). Variabel Kepemimpinan dan Lingkungan Kerja serta Pengaruhnya terhadap Kinerja Karyawan, Management \& Accounting Research Journal, 1(1), 55-62.

Mardikaningsih, R., S. Arifin, A. R. Putra, \& M. Hariani. (2017). The Effect of Motivation and Work Commitment on The Performance of Agricultural Extension Agents, Jurnal Agrimas, 1(2), 115-124.

Mardikaningsih, R. \& D. Darmawan. (2020). Sistem Pengendalian Mutu, Metromedia

Mitchell, T. R., B. C. Holtom, \& T. W. Lee. (2001). How to Keep Your Best Employees: Developing an effective retention policy. Academy of Management Executive, 15, 96-107.

Mobley, W. H., S. O. Horner., \& A. T. Hollingsworth. (1978). An Evaluation of Precursors of Hospital Employee Turnover. The Journal of applied psychology, 63(4), 408-414.

Mosadeghrad, A.M, E. Ferlie, \& D. Rosenberg. (2008). A Study of Relationship between Job Satisfaction, Organizational Commitment and Turnover Intention among Hospital Employees. Health Serv Manage Res., 21, 211-27.

Mueller, J. D. K. (2003). Turnover Processes in a Temporal Context: It's About Time. (online).

Oetomo, Hasan \& D. Darmawan. (2004). Pengaruh Aspek Pendidikan, Pelatihan, Umur dan Pengalaman Kerja terhadap Perilaku Gaya Kepemimpinan, Jurnal Ekonomi-Manajemen, 3(2), 11-22.

Putra, A. R., D. Darmawan, \& E. A. Sinambela. (2017). Pengawasan dan Koordinasi Kerja serta Pengaruhnya terhadap Produktivitas Kerja Karyawan, Akuntabilitas Jurnal Ilmiah Ilmu-ilmu Ekonomi, 10(2), 12-24.

Putra, A. R., E. A. Sinambela. (2021). Pengaruh Kepemimpinan dan Komunikasi Kerja terhadap Kepuasan Kerja Dosen. Jurnal Simki Pedagogia, 4 (1), 58-67.

Retnowati, E. \& E.A. Sinambela. (2019). Pengaruh Komunikasi Kerja dan Integritas terhadap Kinerja Pegawai, Jurnal Ekonomi dan Bisnis, 9(1), 1-10

Retnowati, E. \& U. P. Lestari. (2021). Analysis of The Role of The Work Environment and Ability to Employee Performance, Journal of Engineering \& Social Sciences, 1(1), 16-23.

Santosa, A. \& D. Darmawan. (2002). Hubungan Kepemimpinan, Budaya Organisasi dan Kinerja Karyawan, Jurnal Ilmu Manajemen, 3(2), 81-92.

Sinambela, E. A., R. Mardikaningsih, S. Arifin, \& H. D. Ayu. (2020). Development of Self Competence and Supervision to Achieve Professionalism, Journal of Islamic Economics Perspectives, 1(2), 33-42.

Sinambela, E. A. \& Ernawati. (2021). Analysis of the Role of Experience, Ability and Motivation on Employee Performance, Journal of Social Science Studies, 1(2), 21-26.

Sudja'i \& S. Arifin. (2021). Organizational Culture and Impact on Improving Employee Performance. Journal of Social Science Studies, 1(2), 17-20.

Werdati, Fauchil., D. Darmawan \& N. R. Solihah. (2020). The Role of Remuneration Contribution and Social Support in Organizational Life to Build Work Engagement, Journal of Islamic Economics Perspectives, 1(2), 20-32.

Zeffane, R. (1999). Understanding Employee Turnover: The Need for a Contingency Approach. International Journal of Manpower, 15(9), 1-14. 